\title{
"A poesia é o que recapitula o mundo, chamando-o em cada chama, pela chama de cada sílaba"
}

\author{
Entrevista a \\ Manuel Gusmão'
}

\author{
Marleide Anchieta de Lima \\ (Universidade Federal Fluminense)
}

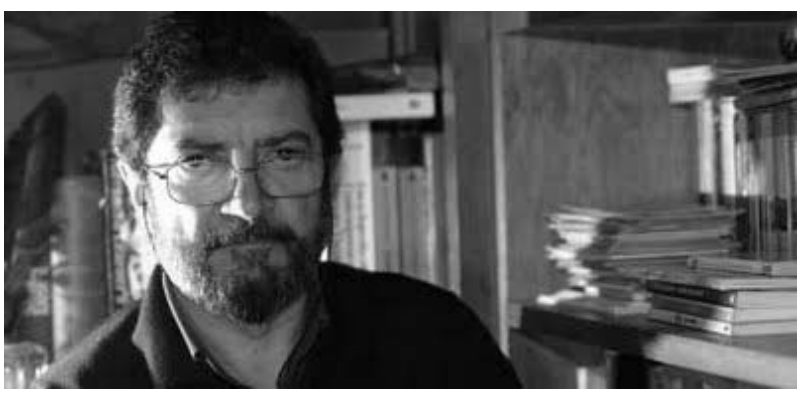

Marleide Anchieta: O que o move a escrever e em que condições escreve?

Manuel Gusmão: Quando ainda era estudante na faculdade, eu era movido pelas discussões que tinha com meus colegas. A partir do segundo ano, encontreime com dois colegas - ficamos amigos - que eram também poetas e publicaram, aliás, antes de mim. São o Joaquim Manuel Magalhães e João Miguel Fernandes Jorge. Muitas vezes os poemas tinham relação com o que líamos e com o diálogo que nós mantínhamos sobre livros que estávamos a ler; outros eram mais nitidamente a nossa procura já de um caminho próprio. Depois continuei a escrever e publicava esparsamente em revistas, mas só editei o primeiro livro já muito tarde, em 1990. Esse foi uma luta para sair, e é talvez isso que me levou a ter a fama de crítico que passa a poeta. De fato, esses meus amigos, o João Miguel, por exemplo, publicou o primeiro livro em 1972, e o Joaquim Manuel Magalhães, em 1974. E eu, quando chegou o 25 de abril, tinha um livro praticamente feito e organizado para a edição. Simplesmente pareceu-me uma coisa desinteressante publicá-lo naquele momento, porque era um momento em Portugal bastante intenso para algumas pessoas como eu e o livro que tinha para publicar não me parecia ter a força necessária. Fui guardando, estudando e trabalhando, entregandome ao mesmo tempo a uma intensa militância política. Por isso só em 1990 é que publiquei.

MA: Poderia falar sobre a relação da sua poesia com as outras artes (o cinema, o teatro, a dança, a música e a pintura)?

MG: Uma das mais fortes será talvez o cinema, sobretudo em Teatros do tempo e Migrações do fogo. Eu sempre fui fascinado por cinema, ainda estudante, havia filmes que me fascinaram e foram ficando comigo até vá-se lá saber quando. O que é 
que o cinema tem de fascinante? É uma arte narrativa. É uma arte narrativa que vive da luz e das sombras, da imagem e que sugere muito mais, por vezes, do que conta. É uma arte narrativa relativamente independente de um olhar subjetivo fundante, de uma figuração específica do narrador. Há filmes, por exemplo, $O$ esplendor dos Ambersons, traduzido em Portugal, por $O$ Quarto Mandamento, do Orson Welles, em que a voz do próprio Orson Welles conta em off a história que as imagens contam, mas isso é raro. É uma arte narrativa, que é uma coisa que a poesia também foi em seus inícios, na Grécia antiga, nos poemas homéricos e não só. Interessa-me bastante a função narrativa da linguagem poética. Hoje, não podemos conceber a narrativa na poesia da mesma maneira que ela foi entendida no passado, porque a própria narrativa literária em prosa e a narrativa cinematográfica desenvolveram e agilizaram imenso os seus procedimentos. Essa dimensão narrativa tem a ver com o tempo e com a escansão do tempo, com os fluxos de imagens e a possibilidade de neles isolar uma. Nós podemos ficar, guardar conosco uma imagem cinematográfica para sempre. Durante anos e anos, essa imagem, em determinadas circunstâncias, reaparece. Ou seja, o fato de essa imagem ser uma pura projeção, jogar com as luzes e as sombras numa sala às escuras, tem um caráter alucinatório, mesmo que seja a imagem mais simples e mais comezinha do cotidiano. Em minha poesia, essa capacidade das palavras suscitarem imagens é uma coisa que me interessa em particular. Basicamente, em relação ao cinema, é isso: por um lado, a técnica alucinatória da imagem e, por outro lado, o tempo e a narração. O que me interessa nas outras artes é, no fundo, em geral, ampliar aquilo que a poesia pode fazer com as palavras apenas, ou seja, levar a poesia a representar não apenas coisas que eu vejo na pintura ou nas imagens cinematográficas, mas a fazer como essas artes fazem, portanto, tentar que a poesia faça o que o cinema faz, ou o que a dança faz, ou a pintura, etc. E, por outro lado, marcar a posição do espectador em relação a essas artes. Há um poema em Mapas, em que eu faço uma descrição (mas isso é raro em mim) de uma pintura de Magritte chamada "Plaisir" /"Pleasure". É uma pintura de 1928, em que uma menina está a comer um pássaro e tem sangue na boca, sangue que lhe cai nos punhos do vestido. A partir daí eu imagino um espectador que está a ver aquela imagem e de repente há um raccord, como se fosse um raccord. Como se alguém estivesse vendo e descrevendo aquele quadro e dissesse: "Este quadro é para ti", oferecendo a outra pessoa uma reprodução do quadro e aquela tentativa de descrição dele. De fato, nunca se trata de apenas descrever uma imagem cinematográfica ou pictórica ou da dança, mas de tentar fazer do modo como elas são feitas, por um lado; e, por outro lado, integrar isso numa narrativa que é minha, ou seja, eu começo a contar uma história e, de repente, meto nessa história um elemento da imagem do cinema ou da dança, etc. Com essas imagens, eu construo uma narrativa ou um poema que não está nelas, mas que se utiliza delas. Nesse sentido, eu não faço exatamente aquilo que chamamos ecfrasis, mas utilizo a inserção dessas imagens para contar outras histórias, reinventar uma história em que aquilo entre também como se fosse eu que o tivesse feito. Há muitos poemas meus onde se veem referências a essas artes várias, mas há também referências a outros discursos não só literários, mas a outros discursos que podemos chamar de material autobiográfico, por exemplo. Há poemas que vêm de cartas que me escreveram, outras que eu escrevi, ou de conversas em que eu participei. Há ali frases que são de outros, que são ditas por outros e que eu importo para minha poesia como uma maneira ainda de estar com eles ou de saudá-los, de dizer "adeus" ou de despedir-me, etc. Por outro lado, a importância dessas várias artes tem a ver com meu interesse com a arte em geral e com a ideia de que as 
artes servem, entre outras coisas, para trabalhar os nossos sentidos, a nossa compreensão e apreciação do mundo que se faz através dos cinco sentidos físicos - o olhar, o olfato, o gosto, o ouvido, o tato - e dos outros. As artes modificam as maneiras dos sentidos funcionarem e, para além disso, modificam os sentidos espirituais, digamos assim, a noção disto e daquilo, do amor, da vida, etc. Nesse sentido, as artes são uma espécie de construtor do humano. Nós somos construções antropológicas em muito moldadas pelas artes e por aquilo que nós usamos delas e com elas fazemos.

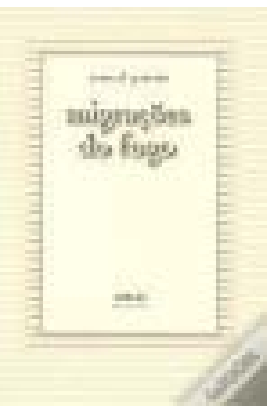

MA: Em Migrações do fogo, observam-se referências a obras cinematográficas e pictóricas. O que o motivou a selecionar determinadas cenas ou pinturas?

MG: Eu roubo o que me interessa para um determinado poema, para o tema ou o clima verbal de um determinado poema... E essas imagens, tenho-as na memória. Posso ter imagens que ainda não utilizei, mas quando num poema vou buscar certas imagens, essas são as que batem certo com o que estou a fazer naquele momento. Por exemplo, há um filme do Wong-Kar Wai, que é o Disponivel para amar [no Brasil, Amor à flor da pele], que me vinha pela lentidão com que nesse filme se filma o andar, assim como pelo fato de o homem e a mulher se cruzarem sem se encontrarem. Ela vai para um lado e ele vai para o outro. Depois, misturei com imagens desse filme, imagens de um outro, agora japonês, em que há um casal que se reencontra depois de anos e anos de terem se conhecido. Não me lembro do nome... é a história de um homem e de uma mulher que se reencontram muito tempo depois de se terem encontrado uma primeira vez. Neste reencontro, a certa altura está cada um no seu quarto de hotel, numa cidade toda construída em altura, torres e mais torres. Num determinado momento, tudo desaparece numa teia de sobreimpressões e de luzes: a iluminação interior dos quartos prolonga-se nos inúmeros focos exteriores de luz; e a certa altura a presença da mulher, de pé no meio do quarto, percebe-se apenas pela presença de uma sombra mais negra e mais opaca. Há um outro também que é o Yi-Yi. Em Yi-Yi, há uma criança que anda todo filme a fazer fotografias. Ele fotografa as personagens de costas, fotografa-lhes a nuca, e só percebemos isso no fim quando vemos as fotografias que ele vai dando às pessoas fotografadas. E é um dom, uma dádiva que ela lhes dá, porque isso é justamente o que as pessoas não podem habitualmente ver de si próprias. Só um terceiro as pode olhar e ver pelas costas. Isso na minha cabeça fez raccord com uma afirmação de Mikhail Bakhtin, em que ele diz que quem quer compreender um texto tem de o tomar, na sua alteridade, como a coisa de um outro. A compreensão ativa (e não há outra) estabelece-se num processo em que experimentamos a exotopia, no tempo, na cultura e na língua. E isso se vê muito simplesmente na fotografia, em que para fazermos um plano a toda a nossa volta, é preciso sempre um outro, o lugar e o olhar de um outro que vai manejando uma máquina e vai filmando.

MA: Assim como a dança, em que o outro compartilha espaços...

MG: O que me fascina na dança é que todo nosso corpo está ali em jogo, e não só o nosso, mas o corpo de outros e, ao mesmo tempo a relação que estabelecemos com a terra sobre a qual dançamos e o espaço que nos cobre e ultrapassa. De certa forma, as posições e os movimentos do nosso corpo estabelecem uma ligação móvel com a terra e os astros. Interessa-me muito a possibilidade de pensar as artes como "técnicas do corpo" (Marcel Mauss). De certa forma, toda arte tem a 
ver com uma parte ou uma parcela ou uma agência do nosso corpo. A pintura tem a ver com o olhar, a mão e a lateralidade e a profundidade de campo, a escultura tem a ver com o corpo do escultor, o corpo a corpo com a massa que ele está a moldar, com as mãos, etc.

MA: Em sua poesia, as imagens da pedra, do mar, do fogo, da rosa e dos mapas aparecem como cronótopos, ou seja, sugerem a espacialização do tempo e, concomitantemente, a temporalização do espaço. Poderia nos falar sobre essa relação espaço, tempo e história presente em sua obra?

MG: A relação com essas palavras tem a ver em parte com o fascínio pelos elementos da matéria, água, fogo, ar, terra, etc. O tema da rosa é um caso particular. O que eu tentei em Dois sóis e a rosa foi chamar "rosa" a "coisas" muito diferentes. Porque a rosa tem sido um símbolo da efemeridade da vida e da beleza: é alguma coisa que morre vinte quatro horas após o seu nascimento. Mas o fato de não ter deixado de ser motivo para a poesia do ocidente ao longo dos séculos dá-lhe um outro tipo de duração. Por outro lado, a rosa é quase como uma cebola, tem camadas, ou pétalas e dentro dela está um oco, um pequeno vazio. Agora, o que isso tem a ver com o espaço e com o tempo? Uma das minhas paixões para além da poesia e das artes é a história. A história, não enquanto escrita dela, mas como fazer da história e, por isso, a questão do tempo é, para mim, uma questão fulcral. Nós temos vários modelos de entendimento do tempo. Por exemplo, o rio e o passar das estações dão-nos imagens diferentes do tempo. O rio parece sempre irreversivelmente ir numa certa direção, tal como a flecha que se atira e que voa em direção a um alvo. O rio e a flecha dão-nos um tempo irreversível, contínuo. O tempo que fatalmente vai dar à morte (ou ao alvo, no caso da seta). É sempre um sítio que nós sabemos que é a morte, ou o mar onde deságua o rio, etc. Mas, por outro lado, o passar das estações, ou uma árvore daquelas que perdem as folhas no inverno ou no outono e renascem na primavera dão-nos uma imagem perceptiva do tempo cíclico. O tempo cíclico foi sempre utilizado pelas sociedades humanas como uma maneira de esconjurar ou de conter o medo da morte, porque o ciclo promete não apenas a passagem dos tempos, mas também a esperança, a promessa de um renascimento constante. Por outro lado, há ainda uma figura do tempo que é a do instante em que se corta ou dá um nó na linha do tempo e isso pode introduzir uma outra temporalidade. Portanto, nós temos uma diversa concepção do tempo a partir de diferentes experiências sensíveis. Isso me interessa. Por outro lado, a temporalidade histórica acrescenta mais outras figuras a estas. A temporalidade histórica, para mim, é muito pensada na base de Walter Benjamin, como algo que implica o corte do tempo uniforme, contínuo, homogêneo, e esse corte é a possibilidade de um tempo messiânico, embora sem Messias. O que se diz para o messianismo vale também para o materialismo histórico? O que é a revolução? A paragem do tempo e o fato de ficar no limiar do tempo, como se o tempo recomeçasse. O tempo vai (re)começar outra vez. Ora, nessas minhas ideias, a temporalização do espaço é fato fundamental para responder à espacialização do tempo, porque a espacialização do tempo, digamos, espalma e reduz a espessura temporal e a distribui por um espaço. As cidades contemporâneas, por exemplo, uma cidade que tem um certo passado dá muito exemplo disso. Nós vamos a um espaço, a uma rua e temos edifícios que vêm de períodos diferentes e que se dispõem num mesmo plano espacial. Em Lisboa, podemos ver isso, podemos ver o tempo espacializado. Por exemplo, pensar em certo tipo de construções arquitetônicas. Podemos ver um edifício todo em vidro ou em metal, mas que tem bocadinhos de parede antiga, que pode ser medieval, 
incrustados ainda. Ora, o que isso significa? Temos aí uma espécie de objetos que marcam diferentes tempos e, quando eu vejo o tempo espacializado na rua, posso em qualquer momento isolar um edifício e dizer: "Este edifício foi construído em 1940 e este edifício, ao lado, foi em 2000". O que é que os diferencia? O tempo pode introduzir-se no espaço e mostrar que o espaço está disposto segundo um tempo. São figurações que restaram do tempo passado. Por exemplo, há ruas de Lisboa de onde desapareceram os prédios que eu conheci quando era jovem. Eu sei que estava lá outra coisa e dessa coisa não ficou nada, mas, se eu for trabalhar com documentos sobre aquela rua, encontrarei a prova disso, de que ali estava um edifício que lá já não está. Tudo isso é tempo. Portanto, o tempo, para mim, é, também e ainda, a promessa de sua interrupção, enquanto história já contada, e de começo de uma outra história ou de um outro tempo.

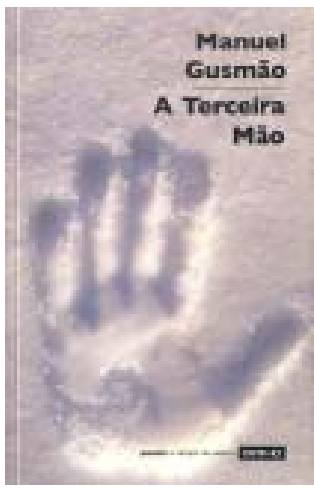

MA: No livro $A$ terceira mão, o senhor fala das mãos que escrevem, inscrevem e reescrevem, mobilizando tempos e espaços. De certa forma, o livro parece destacar as mãos de Carlos de Oliveira, Herberto Helder, Fiama e outras. Como esses poetas tão diferentes entre si se harmonizam (se encontram) em sua escrita?

MG: A ideia da terceira mão é a ideia de que no fundamental minha mão, ou maneira, é uma terceira mão, que não é nem a de Carlos de Oliveira, nem a de Herberto Helder (basicamente são esses dois que me fascinam). São os dois polos, os dois ímãs mais fortes. Essa é uma ideia que eu já expus uma vez oralmente numa conferência. São poetas muitíssimo diferentes. $\mathrm{O}$ Carlos de Oliveira vem do neo-realismo e o Herberto vem do surrealismo, mas é um surrealismo muito particular, muito sui generis. São dois poetas que formam duas polaridades entre as quais se distribui o resto da poesia portuguesa. Eu tendo a pensar que os dois ocupam lugares opostos, mas, como uma força magnética, atraem-se um ao outro. Carlos de Oliveira, na obra final, naquele livro magnífico, um dos mais belos livros de poemetos da poesia portuguesa, que é Pastoral, seu último livro de poemas, consegue aquele estado de contenção, de elipse, de construção gráfica das imagens, de despedida e de agonia perante a fatalidade da morte. É tão forte que só é comparável com o êxtase enérgico, com a exuberância discursiva de Herberto Helder. De fato, neste meu livro A terceira mão, há poemas que exploram motivos do Carlos de Oliveira, mas para fazer algo de diferente. Há aqui um poema que fala de alguém que passa por um posto de gasolina e isso é uma situação que eu vou buscar a um poema do Carlos de Oliveira que se chama "Posto de gasolina" (de Sobre o lado esquerdo), em que o moço empregado do posto se interroga: "Quem sou eu, no entanto, que balança tenho para pesar sem erro a minha vida e os sonhos de quem passa?". Ora, o que eu faço com isso é uma variação a que acrescento uma dimensão ou um tom de conversa ou de relato e um ethos emocional que o poema de Carlos de Oliveira não tem. Do mesmo modo, este poema em prosa, "Dunas", que se desdobra em quatro, parte de um poema, com o mesmo título de Sobre o lado esquerdo, de Carlos de Oliveira. Aqui, começo por alterar a referência da palavra que passa a ser o aspecto de dunas que têm, por exemplo, as circunvoluções cerebrais; depois transponho essa palavra para um outro tipo de discurso, conto uma história inventada, uma ficção que tem de qualquer modo a ver com uma intervenção cirúrgica a que fui submetido. Logo, a coisa pode ser lida nessa clave ou com essa chave, e o poema liga, então, um gesto de poética e um gesto autobiográfico; ou então o leitor ignora esse lado 
autobiográfico e procura apenas o confronto poético e retórico entre os dois poemas. Quanto ao Herberto Helder, não me atrevo a fazer sequer coisas parecidas com o uso do pastiche. Um poema em que eu fico mais próximo dele é um em que utilizo, pondo entre aspas ou em itálico, versos dele, mas também de outros como a Luiza [Neto Jorge] ou o [Mário] Cesariny: é um poema meu, mas apenas na medida em que como que sobro dos outros. Neste poema, "música da mão esquerda", é uma expressão do Herberto; "deslocando na arquictetura do silêncio, os blocos e as linhas do som/ o gesto de uma antropologia augural", isto é um comentário sobre um poema do Herberto; "os dedos negros" já é verso do Herberto; "ouvem o grito dos mortos de um lado ao outro/ do mundo" é de um poema em que o Herberto, por sua vez, utiliza material verbal do Húmus do Raul Brandão. "Florestas de Pedra e púrpura" é de Carlos de Oliveira; "escrevem o poeta "nos recessos mais baixos"”, Herberto; "nos cornos que ele traz à cintura com a elegância selvagem/ e inata do leopardo", estas são imagens do Herberto; "caligrafia sumptuosa - punti luminosi", Herberto, que está a citar Ezra Pound; "energicamente as capitais do corpo", "as capitais do corpo" é Luiza. "Era depois da morte, "Redivivo"”, Herberto e Ruy Belo, citando-o. Quanto à Fiama, dedico-lhe um poema na $1^{a}$ sequência do livro que responde a um poema dela dedicado a Carlos de Oliveira e a Luiza Neto Jorge, com base numa coincidência nas nossas histórias de vida.

MA: Em A terceira mão, o senhor visita obras de Carlos de Oliveira. Há, inclusive, uma citação a "Soneto", poema presente no livro Cantata. Pensando nos versos que cita, pergunto como pode o poema "recriar o mundo pedra a pedra"?

MG: Carlos de Oliveira usa essa expressão "pedra a pedra" e num outro poema diz "chama a chama". O Herberto Helder junta as duas expressões "pedra a pedra, chama a chama", num outro poema. Isso é muito curioso, dois poetas que são completamente diferentes e passam pelas mesmas imagens. "Pedra a pedra" é uma metáfora, "pedra a pedra" ou "chama a chama" significa palavra a palavra e, nesse sentido "recria" como quem suscita ou convoca o mundo a ser. Mas o que eu sugiro que se veja neste poema é também uma importação de um dos poetas de que mais gosto, de Rimbaud. Eu uso o Carlos de Oliveira para ler em "levantar a torre do meu canto/ e recriar o mundo pedra a pedra/ uma espécie de eco tão próximo, tão estranho/ e tão íntimo, o eco só que fosse daquela Canção da mais alta torre". Ora, Chanson de la plus haute tour é o título de um poema de Rimbaud, cuja $1^{a}$ estrofe é assim: "Oisive jeunesse/ À tout asservie,/ Par délicatesse/ J'ai perdu ma vie./ Ah! Que le temps vienne/ Où les coeurs s'éprennent”. Portanto, construir o mundo pedra a pedra é a ideia de que as palavras que vão se construindo e construindo o poema, têm o poder de suscitar nos outros e em nós, como vemos em outros poetas, imagens do mundo. Portanto, é como se nós estivéssemos a construir o mundo quando lemos a poesia ou um romance, quando ouvimos música, etc. Mundo material a alterar o mundo tal como o conhecíamos. Fazemos nossos próprios sentidos. Há coisas do mundo para as quais minha percepção está intimamente ligada a palavras. Por exemplo, a aurora. A aurora eu nunca dissociei ou serei capaz de dissociar de certos poemas de Rimbaud. Como não sou capaz de dissociar certos versos de Rimbaud de imagens de filme de Nicholas Ray, creio que se chama Wings Across the Everglades, em que há uns pássaros, uma espécie de flamingos cor de rosa que estão nos arbustos num campo. Nós não os vemos, só vemos galhos de formas confusas, verde escuro. De repente, eles levantam voo em conjunto, quase num só movimento, em uníssono. Isso é, para mim, a imagem visual que corresponde ao verso do batean irre, de Rimbaud : 
"L'Aube exaltée ainsi qu'un peuple de colombes". Portanto, construir o mundo é isso. Nós temos uma palavra e essa palavra podemos dar-lhe um efeito de suscitação augural sobre o mundo. Em última instância, isto vem da ideia de que o poeta foi no passado (já não é, não pode ser, ou é-o de outra maneira) uma espécie de mago: "Faça-se água" e a rocha começa a deitar água.

MA: Em Portugal, sua poesia demonstra boa recepção por parte da crítica literária. Os prêmios que recebeu confirmam isso. Há algum aspecto mencionado pela crítica que o senhor não reconheça em sua obra? E, inversamente, há algo que julgue relevante e que a crítica ainda não tenha apontado?

MG: Por um lado, eu penso que alguns críticos, que têm lido mais a sério minha obra, têm visto coisas pertinentes, embora por vezes custa-me entender algumas coisas que dizem. Por exemplo, não estou muito de acordo com alguém que, aliás, respeito muito e que diz que a minha poesia é, sobretudo, intelectualizada, é fortemente intelectual, racional. Eu penso que isso tem a ver com o fato de haver determinados posicionamentos filosóficos, históricos ou políticos, que transparecem. Há versos meus que são quase suposições de natureza teórica, mas que são para obter um efeito, e um efeito que é da ordem do emocional, do afetivo e não do puramente intelectual. Por outro lado, eu também afirmo que a poesia pensa, não é só a filosofia que pensa. E no que o pensamento da poesia se diferencia do pensamento da filosofia? A poesia está amarrada à linguagem comum, à língua que todos falamos e, portanto, ela se faz do jogo com essa linguagem, ela é o prazer com essa materialidade sonora e gráfica que é a da língua. Há uma cantiga de amigo famosíssima, de D. Dinis, em que o refrão diz: "Ai, Deus e u é?" Ora, isto para mim é lindíssimo e é puramente oral, auditivo - "Ai, Deus e u é?". "Ai, flores, ai, flores do verde pino/ se sabedes novas do meu amigo?/ Ai, Deus e u é?". A poesia aceita isso, aceita ficar presa, jogar e gozar com a materialidade gráfica e sonora da língua. Aceita, no fundo, a prisão na linguagem. Enquanto a filosofia tenta sublimar isso, superar e afastar-se disso. Há uma longa história da filosofia, desde Platão, a dizer que os poetas são gente efeminada, gente que gosta demasiado da retórica, e a criticar a ficção porque é mentirosa. Há um texto de John Locke, em que ele diz que o que é necessário é a linguagem como uma espécie de canalização que levasse a água diretamente ao espírito dos leitores, mantendo-a pura, ou seja, não pondo em causa a univocidade do sentido das palavras, abolindo completamente as imagens e as metáforas. Ele não se dá conta de que a proposta da linguagem como uma canalização é já metáfora. Kant e outros filósofos estão cheios de metáforas fundacionais que se ignoram. A poesia, por seu turno, prefere entregar-se a essa proliferação do sentido. A poesia pensa, mas apaixonadamente imersa na linguagem. Na minha poesia, há um pensamento que se exprime poeticamente, penso eu, e não apenas intelectualmente. Nesse sentido, eu poderia dizer que a poesia é uma razão, mas uma razão de outro tipo. Perder o contato com a poesia é um risco de perder não apenas algo dos afetos e das emoções, mas de perder uma outra maneira de pensar. Depois, eu diria que a poesia é uma espécie de razão apaixonada, razão ardente. O próprio Apollinaire tem um verso em que o diz: "raison ardente", razão ardente. E há um poeta sobre o qual fiz minha tese de doutoramento, um poeta francês, Francis Ponge, que, jogando com as letras e com as palavras, diz que a poesia é un réson e depois explica: "une raison qui résonne", uma razão que ressoa. É isso que me interessa. Depois há valorizações excessivas do fato de a minha poesia citar outros livros, outros autores, outros trechos da poesia, da filosofia... Minha poesia não pretende ser uma poesia culturalista; essas citações não são para eu exibir cultura; fazem 
parte da coralidade que eu gostaria de introduzir no que parece ser uma fala individual, de tal modo que essa pluralidade de vozes tece a intimidade do meu ser.

MA: O que o senhor pensa a respeito da recente poesia que circula no mercado editorial português?

MG: Há poetas interessantes nessas últimas décadas, mas ultimamente o que tem dominado a atenção é um conjunto de poetas que tem uma poética muito afirmativa, dizendo que não pode haver mais metáforas e imagens em poesia. A poesia tem que ser a linguagem mais chã possível. Há um ou outro que não é mau, porque um poeta com talento aguenta qualquer tipo de poética, mesmo que equivocada. Agora, em muitos casos, aquela poesia não consegue me convencer. E eu não tenho a ideia de que no meu tempo é que era bom. Mas eu penso que há um equívoco em relação a alguns desses poetas. Eles acham que aquilo é que está no ar do tempo, que é aquilo que o tempo espera dos poetas conscientes. Ora, eu acho que não. Eu acho que, se eu não gosto dos tempos que estamos a viver na contemporaneidade, tenho de arranjar maneira de falar contra o tempo, contra o contemporâneo. Eu falo agora contra o agora, espero ser intempestivo e não um acomodado. Estou fora do tempo e julgo este tempo, dizendo que isso tudo é lixo. Eu posso fazer isso. Agora, vou repetir a ideia de que este tempo é um tempo medíocre, em que o espetáculo e o mercado dominam tudo, mas imitar isso, aí é que eu não vejo qual o interesse. Isto não esconde que haja condições para haver outros poetas. Por exemplo, nos anos 80 e 90, apareceram em livro poetas que têm uma força inegável, que é a força que a poesia pode ter. Por exemplo, Fátima Maldonado, Luís Miguel Nava ou o Fernando Guerreiro, que é um poeta obscuro, hermético, difícil, mas interessantíssimo. Depois, há o Daniel Faria, que já morreu, morreu muito novo, muito bom, um poeta com uma capacidade de imaginação verbal muito forte. Ora, um dos poetas que eu, apesar de tudo, respeito e parece-me o mais interessante desses mais recentes, é um poeta onde, nos últimos livros que li dele, acontece uma coisa interessante. Ele publica quase todos os anos um livro (às vezes dois, são como plaquetes, são livros muito curtos com muito poucos poemas e colados a uma experiência do real). Portanto, dá a sensação de que está criando uma espécie de diário, que ele faz em pequenos ciclos, como, por exemplo, "Eu fui à Noruega", então faz uma série de poemas sobre a Noruega. Ele vai a uma taberna e recorda-se de outras aonde ia e faz um poema sobre tabernas. E, em quase todos eles, os últimos versos têm a ver com a morte. É Manuel de Freitas.

\section{NOTAS}

1. Agradeço à Carla Miguelote pelo auxílio durante a gravação e a edição da entrevista; à professora Ida Alves, pelo incentivo, pela colaboração e leitura atenta do referido trabalho; e, ao poeta Manuel Gusmão, pela atenção e generosidade com que nos transmitiu seus conhecimentos, além de ler e revisar o texto, possibilitando a concretização desse projeto. 